\title{
Country and Political Risk Analysis of Spanish Multinational Enterprises Using Exploratory Projection Pursuit
}

\author{
Alfredo Jiménez ${ }^{1}$, Álvaro Herrero ${ }^{2}$, and Emilio Corchado ${ }^{2}$ \\ ${ }^{1}$ Department of Economics and Business Administration \\ University of Burgos, Spain \\ alfredojimenezpalmero@hotmail.com \\ ${ }^{2}$ Department of Civil Engineering. University of Burgos, Spain \\ C/ Francisco de Vitoria s/n, 09006 Burgos, Spain \\ \{ahcosio, escorchado\} @ubu.es
}

\begin{abstract}
As part of a multidisciplinary research project on relevant applications of Exploratory Projection Pursuit, this study sets out to examine levels of country and political risk that are assumed by a sample of Spanish Multinational Enterprises (MNEs). It analyses information pertaining to points such as decisions over the localization of subsidiary firms in various regions across the world, the importance accorded to such decisions and the driving forces behind them. The specific variables under study are economic freedoms, perceived levels of corruption and the constraints affecting the host governments in a sample of 1773 Spanish MNE subsidiaries throughout the world. Several neural projection models are applied, and we are able to conclude that these connectionist techniques help analyse the relevant data to identify the internationalization strategies of Spanish MNEs, their underlying motives and the goals they pursue.
\end{abstract}

Keywords: multinational firm, country and political risk, foreign direct investment, exploratory projection pursuit, unsupervised learning.

\section{Introduction}

Internationalization is a decision that firms must take with increasing frequency, as competition in many sectors due to globalization, obliges companies to enter international markets in the search for new markets and lower operating costs. Thus, the decision to become a Multinational Enterprise (MNE) and the challenge of successfully undertaking such a transformation are more relevant than ever. Numerous works have sought to clarify the factors that are involved in decisions concerning the localization of foreign investments, whether between developed countries, from developed countries to developing countries or, to a lesser extent, vice-versa from developing to developed countries.

[1] contains an interesting table with an abundant bibliography of empirical studies concerned with analyzing the importance of certain factors that attract investments. However, it may be seen how the analysis of political risk as a fundamental factor in the localization of direct investment, constitutes a field that has received much less 
attention that other factors, with the notable exceptions of Marois [2], [3] for French MNEs, Rich and Mahmoud [4] for Canadian MNEs, Mortanges and Aller [5] for Dutch MNEs, Mutinelli and Picitello [6] for the Italian ones and Noordin et al [7], the last-named being one of the few works centred on multinational firms in a lessdeveloped countries, in this case Malaysia. That is despite some surveys which show that on occasions even $100 \%$ of the firms consulted performed assessments of the political risk to which their subsidiaries were exposed [8].

Visualisation techniques have been employed to analyse large datasets for some time. They are considered a viable approach in the search for information and they present it on graphic display devices that highlight different characteristics and allow anomalies to be detected by the relevant decision-makers [9].

The identification of patterns that exist across dimensional boundaries in high dimensional datasets is a challenging task. Such patterns may become visible if changes are made, to the spatial coordinates; however an a priori decision, as to which parameters will reveal most patterns, requires prior knowledge of the unknown patterns.

In this study, EPP models are applied to analyze the internal structures of the aforementioned case study on the role of country and political risk in the localization decisions of Spanish MNEs. The paper is structured as follows. Section 2 outlines the application of dimensionality reduction techniques for data analysis and also describes the main neural projection model applied in this work. Section 3 sets out the dataset on country and political risk, while section 4 presents the results and, finally, Section 5 summarizes the conclusions and the future lines of research.

\section{Dimensionality Reduction Visualization for Data Analysis}

Projection methods project high-dimensional data points onto lower dimensions in order to identify "interesting" directions in terms of any specific index or projection. Such indexes or projections are, for example, based on the identification of directions that account for the largest variance of a dataset (such as Principal Component Analysis (PCA) [10], [11], [12]) or the identification of higher order statistics such as the skew or kurtosis index, as in the case of Exploratory Projection Pursuit (EPP) [13]. Having identified the interesting projections, the data is then projected onto a lower dimensional subspace plotted in two or three dimensions, which makes it possible to examine its structure with the naked eye. The remaining dimensions are discarded as they mainly relate to a very small percentage of the information or the dataset structure. In that way, the structure identified through a multivariable dataset may be visually analysed with greater ease.

The combination of this type of technique together with the use of scatter plot matrixes constitutes a very useful visualization tool to investigate the intrinsic structure of multidimensional datasets, allowing experts to study the relations between different components, factors or projections, depending on the technique that is used.

\subsection{The Unsupervised Connectionist Model}

The standard statistical EPP method [13] provides a linear projection of a dataset, but it projects the data onto a set of basic vectors which best reveal the interesting 
structure in data; interestingness is usually defined in terms of how far the distribution is from the Gaussian distribution.

One neural implementation of EPP is Maximum-Likelihood Hebbian Learning (MLHL) [14], [15], which identifies interestingness by maximising the probability of the residuals under specific probability density functions that are non-Gaussian.

An extended version of this model is the Cooperative Maximum-Likelihood Hebbian Learning (CMLHL) [16] model. CMLHL, which is based on MLHL [14], [15] adds lateral connections [16], [17] which have been derived from the Rectified Gaussian Distribution [18]. The resultant net can find the independent factors of a data set but does so in a way that captures some type of global ordering in the data set.

Considering an $\mathrm{N}$-dimensional input vector $(x)$, and an M-dimensional output vector ( $y$ ), with $W_{i j}$ being the weight (linking input $j$ to output $i$ ), then CMLHL can be expressed [16], [17] as:

1. Feed-forward step:

$$
y_{i}=\sum_{j=1}^{\mathbf{N}} W_{i j} x_{j}, \forall i .
$$

2. Lateral activation passing:

$$
y_{i}(t+1)=\left[y_{i}(t)+\tau(b-A y)\right]^{+} .
$$

3. Feedback step:

$$
e_{j}=x_{j}-\sum_{i=1}^{M} W_{i j} y_{i}, \forall j
$$

4. Weight change:

$$
\Delta W_{i j}=\eta \cdot y_{i} \cdot \operatorname{sign}\left(e_{j}\right)\left|e_{j}\right|^{p-1} .
$$

Where: $\eta$ is the learning rate, $\tau$ is the "strength" of the lateral connections, $b$ the bias parameter, $p$ a parameter related to the energy function [14], [15], [16] and $A$ a symmetric matrix used to modify the response to the data [16]. The effect of this matrix is based on the relation between the distances separating the output neurons.

\section{Country and Political Risk Dataset}

The empirical part of this work seeks to describe the principal characteristics of country and political risk which influence the localization and the presence in foreign countries of Spanish MNEs, while controlling for the effects of variables related both to the firm and to the country.

The sample of firms on which the present study is based is made up of Spanish multinational firms of over 250 employees, which in December 2007 appeared on the list of the Instituto de Comercio Exterior [Institute of Foreign Commerce] (ICEX), the www.oficinascomerciales.es web page, and other foreign bodies concerned with foreign direct investment contactable through the ICEX that provide directories of Spanish MNEs with investments in their countries. 
In total the sample is formed of 166 Spanish MNEs, which have 1812 subsidiaries localized across the world, for which the data on the necessary variables was obtained for 1773 subsidiaries, which represents $97.7 \%$ of all cases. The dataset is composed of 1152 observations relating to 12 variables, namely: Index of Economic Freedom, Corruption Perceptions Index, Political Constraints Index (POLCON), total assets, employee numbers, Return on Equity (ROE), growth rate of sales, solvency ratio, number of foreign countries in which the MNE has its subsidiaries, Foreign Direct Investment/Gross Domestic Product (FDI/GDP), GDP growth as a measure of the appeal of the country, and total population as a measure of size.

\section{Experiment, Results and Comparison}

CMLHL was applied to the above dataset (See Section 3). The projections obtained by this model are set out below and analyzed in this section.

It can be seen that the CMLHL projection (Fig.1) reflected the different motivations driving Spanish MNEs to localize in the countries of the different regions under analysis, which represent, to a great degree, the main host countries traditionally targeted by Spanish foreign direct investment.

It may be seen that group 1 (Fig. 1) is made up of smaller firms that can not afford to overspend scarce resources on risky internationalization strategies. Something similar happens in group 2, where small firms dedicated to the services sector are concentrated, and in which two subgroups may be seen in accordance with the countries that they were targeting.

Group 3 (Fig. 1) however, refers to firms with quite different characteristics which are, above all, large firms in the manufacturing sector with complex internationalization strategies as a result of the high volume of resources that they are able to invest.

For its part, Group 4 (Fig. 1) contains the densest subgroups in the entire sample. They show a grouping of firms within the currently controversial construction sector that has targeted developed economies with large markets as well as countries that have recently joined the European Union, and which has greater expectations for growth and profitability. However, the existence of subgroups where the presence of Eastern European countries is very predominant, which is the case of subgroup 4.1 (Fig. 1), demonstrates that these countries, despite having achieved important economic, social and institutional progress, still constitute an investment destination with specific characteristics that distinguish them from the other member States of the European community, which is congruent with the results obtained by Durán, de la Fuente and Jiménez (2008b).

Group 5 (Fig. 1) from among all of the subgroups shows that some multinationals seek to minimize the risks associated with investment in countries with close cultural ties, thereby seeking better management and easier solutions to any potential problems that might arise.

Group 6 (Fig. 1) is very interesting as it is made up of the flagships of Spanish foreign investment, and in addition shows a certain short-termism in its investment strategy in Latin America, seeking to achieve a competitive advantage at the start of the investment, but unconcerned about its inherent problems that relate to political risk. 


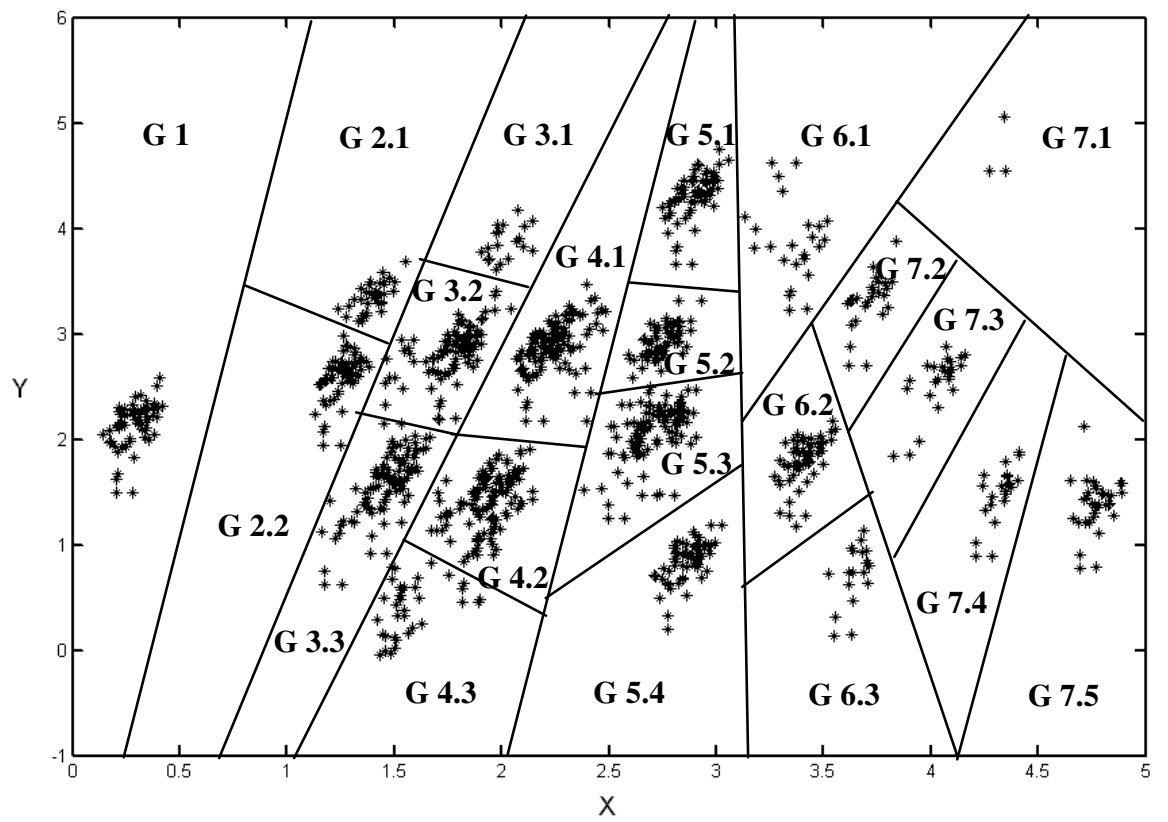

Fig. 1. CMLHL projection for the data set

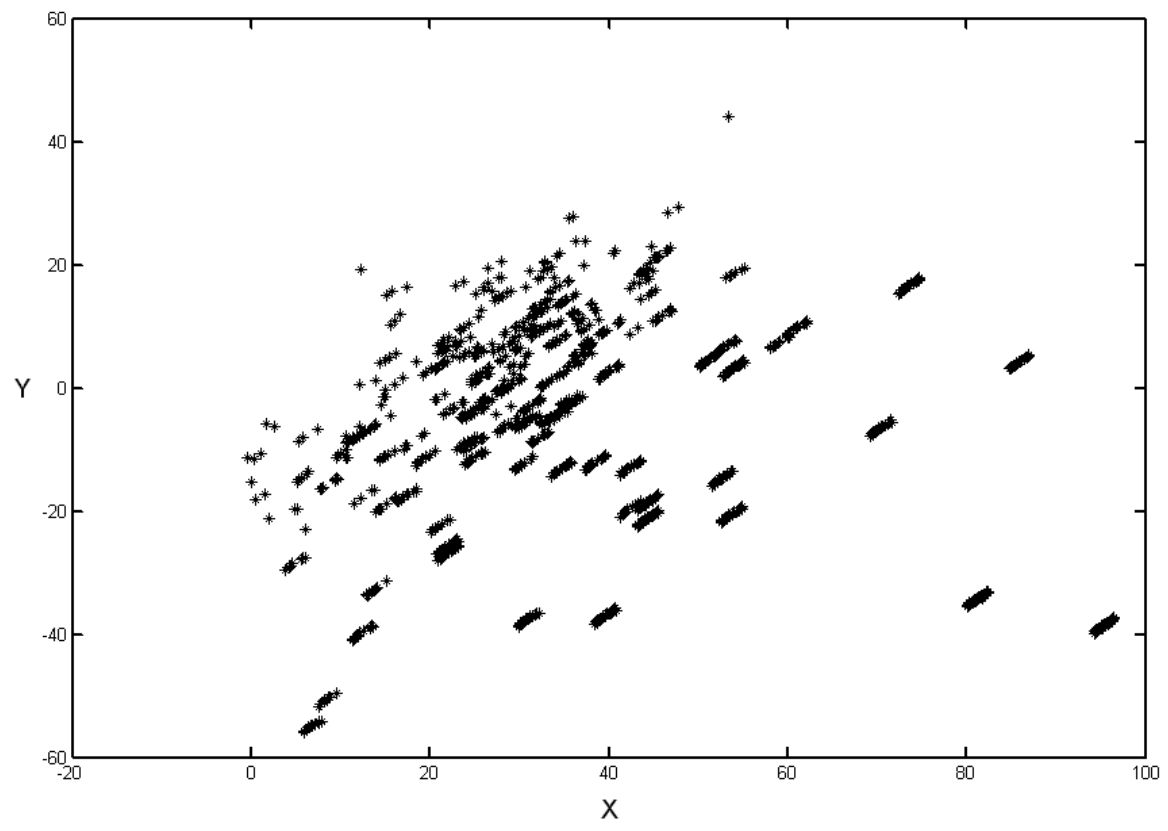

Fig. 2. PCA projection for the data set 


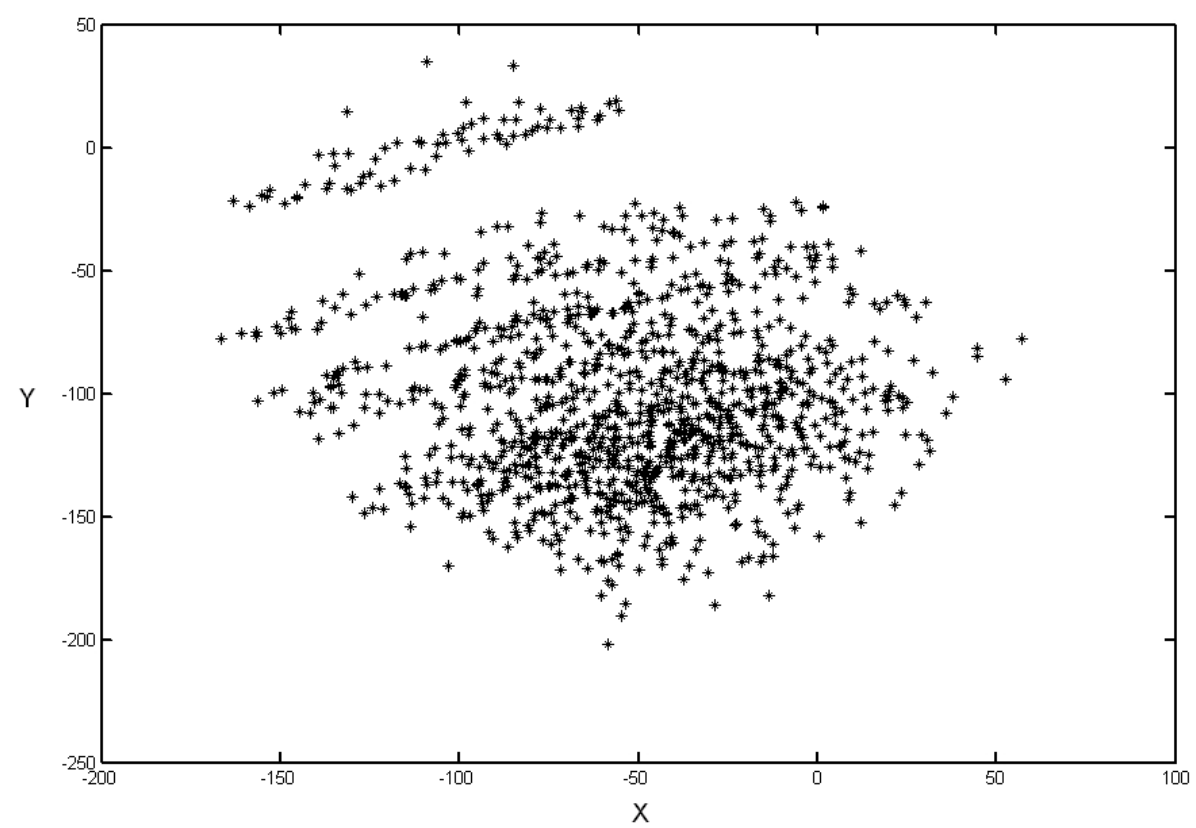

Fig. 3. CCA projection for the data set

Finally, Group 7 (Fig. 1) constitutes a set of localizations with the highest number of subgroups, and in all of them the high dispersion between their constituent elements may easily be appreciated. Those firms with the least clear internationalization strategies appear here, and at times are similar to those of other groups, but in different countries or other sectors.

Some other well-known projection models, namely Principal Component Analysis (PCA) [10], [11], [12] and Curvilinear Component Analysis (CCA) [19] were applied to confirm the validity of the results. Figs. 2 and 3 show the projections obtained by these models.

Fig 2. presents the projection obtained by PCA through the two first principal components. As it can be seen, PCA is able to show the structure of the dataset but in a less clear way than CMLHL (Fig. 1).

Fig 3. presents the projection obtained CCA. In this case, CCA is not able to show the inner structure of the data, as only 2 main groups could be differentiated.

CMLHL (Fig. 1) clearly obtains a clearer and more widely spread projection than both PCA (Fig. 2) and CCA (Fig. 3), allowing more visual information to be extracted, which in turn enables clearer and better conclusions to be drawn from the data.

\section{Conclusions and Future Work}

In brief, we can conclude that this study has served to show the different reasons underlying the internationalization strategies of Spanish MNEs and the different goals 
they pursue, which may be appreciated from the different groups identified by CMLHL, localizing in a specific country according to their specific needs or those of their sector, as is evinced by the different subgroups.

Future work will focus on the study of more international areas and also of international companies other than the Spanish ones. Also other unsupervised neural models such as topology preserving maps will be applied, for comparison purposes, to this interesting case study.

Acknowledgments. This research has been partially funded through project BU006A08 of the JCyL.

\section{References}

1. Galan, J.I., Gonzalez-Benito, J., Zuniga-Vincente, J.A.: Factors Determining the Location Decisions of Spanish MNEs: An Analysis based on the Investment Development Path. J. Int. Bus. Stud. 38(6), 975-997 (2007)

2. Marois, B.: Assessment and Management of Political Risk: Practice of French Firms. In: Annual Meeting of the Academy of International Business, London (1979)

3. Marois, B.: Comment les Enterprises Francaises Gerent le Risque Politique. Revue Francaise de Gestion, 4-9 (May-August 1981)

4. Rich, G., Mahmoud, E.: Political Risk Forecasting by Canadian Firms. International Journal of Forecasting 6(1), 89-102 (1990)

5. Mortanges, C.P.d., Allers, V.: Political Risk Assessment: Theory and the Experience of Dutch Firms. International Business Review 5(3), 303-318 (1996)

6. Mutinelli, M., Piscitello, L.: Differences in the Strategic Orientation of Italian MNEs in Central and Eastern Europe. The Influence of Firm-specific Factors. International Business Review 6(2), 185-205 (1997)

7. Noordin, B.A., Harjito, D.A., Hazir, A.Y.: Political Risk Assessment of Malaysian based Multinational Corporation. Problems and Perspectives in Management 4(3), 91-99 (2006)

8. Hashmi, M.A., Guvenli, T.: Importance of Political Risk Assessment Function in U.S. Multinational Corporations. Global Finance Journal 3(2), 137-144 (1992)

9. Ahlberg, C., Shneiderman, B.: Visual Information Seeking: Tight Coupling of Dynamic Query Filters with Starfield Displays. In: Proceedings of the SIGCHI conference on $\mathrm{Hu}-$ man Factors in Computing Systems. ACM, New York (1994)

10. Hotelling, H.: Analysis of a Complex of Statistical Variables Into Principal Components. Journal of Education Psychology 24, 417-444 (1933)

11. Pearson, K.: On Lines and Planes of Closest Fit to Systems of Points in Space. Philosophical Magazine 2(6), 559-572 (1901)

12. Oja, E.: Neural networks, principal components, and subspaces. Int. Journal of Neural Systems 1, 61-68 (1989)

13. Friedman, J.H., Tukey, J.W.: A Projection Pursuit Algorithm for Exploratory DataAnalysis. IEEE Transactions on Computers 23(9), 881-890 (1974)

14. Corchado, E., MacDonald, D., Fyfe, C.: Maximum and Minimum Likelihood Hebbian Learning for Exploratory Projection Pursuit. Data Mining and Knowledge Discovery 8(3), 203-225 (2004)

15. Fyfe, C., Corchado, E.: Maximum Likelihood Hebbian Rules. In: Proc. of the 10th European Symposium on Artificial Neural Networks (ESANN 2002), pp. 143-148 (2002) 
16. Corchado, E., Fyfe, C.: Connectionist Techniques for the Identification and Suppression of Interfering Underlying Factors. Int. Journal of Pattern Recognition and Artificial Intelligence 17(8), 1447-1466 (2003)

17. Corchado, E., Han, Y., Fyfe, C.: Structuring Global Responses of Local Filters Using Lateral Connections. Journal of Experimental \& Theoretical Artificial Intelligence 15(4), 473487 (2003)

18. Seung, H.S., Socci, N.D., Lee, D.: The Rectified Gaussian Distribution. Advances in Neural Information Processing Systems 10, 350-356 (1998)

19. Demartines, P., Herault, J.: Curvilinear Component Analysis: A Self-Organizing Neural Network for Nonlinear Mapping of Data Sets. IEEE Transactions on Neural Networks 8(1), 148-154 (1997) 